\title{
CONTRIBUIÇÕES PARA A CONSTRUÇÃO DO CONHECIMENTO CIENTÍFICO EM TURISMO: UMA ANÁLISE BIBLIOMÉTRICA DOS ARTIGOS PUBLICADOS NO ENANPAD ENTRE 1997 E 2006
}

\author{
CONTRIBUTIONS FOR THE CONSTRUCTION OF THE SCIENTIFIC \\ KNOWLEDGE IN TOURISM: A BIBLIOMETRIC ANALYSIS OF ARTICLES \\ PUBLISHED IN THE ENANPAD BETWEEN 1997 AND 2006
}

Maria José Barbosa de Souza - mjbsouza@matrix.com.br Professora da Universidade do Vale do Itajaí - UNIVALI Gilberto Pimentel Filho - gibapimentel@ bol.com.br Professor das Fac. Integradas de Vitória de Santo Antão e Universidade de Pernambuco Simone de Faria - monefaria06@yahoo.com.br Acadêmica do Curso de Administração e Bolsista de Iniciação Científica (PROBIC) DA Universidade do Vale do Itajaí - UNIVALI

\begin{abstract}
RESUMO
A produção acadêmica apresentada em eventos científicos constitui-se em importante base de dados para estudos e a tecnologia da informação, através da bibliometria, tem propiciado a realização de pesquisas sobre a evolução dessa produção, pois os estudos bibliométricos são úteis para avaliar a produção de um grupo de pesquisadores sobre um tema específico em um dado período. Com o objetivo de analisar a produção científica na área de turismo, publicada nos anais do EnANPAD - Encontro da Associação Nacional de Pesquisa e Pós-Graduação em Administração, entre 1997 e 2006, realizou-se um estudo bibliométrico, de caráter exploratório-descritivo, que identificou 67 artigos sobre turismo e hotelaria, apresentados nesse evento, no período considerado, e constatou expressiva evolução na quantidade de trabalhos apresentados, anualmente, que cresceu de 3 artigos em 1997 para 18 em 2006. A pesquisa revelou também os autores que estão publicando no referido evento, as instituições às quais estão vinculados e os assuntos relacionados a turismo que têm despertado o interesse da comunidade acadêmica.
\end{abstract}

Palavras-chave: Turismo; Pesquisa em turismo; Estudo bibliométrico.

\section{INTRODUÇÃO}

Em virtude de suas características e dos impactos ambientais, econômicos, sociais e culturais que a exploração de sua atividade pode causar em uma localidade, o turismo é uma área de estudos multidisciplinar, campo de interesse de pesquisadores de outras áreas, como a geografia, a administração, a economia e a sociologia, por exemplo, além do próprio turismo. Temas como motivação para o turismo, relacionamento anfitrião-hóspede, criação de novos empreendimentos, marketing de localidades, estudos dos espaços turísticos, comportamento do turista, arquitetura de equipamentos turísticos, gerenciamento de transportes, administração de hotéis e restaurantes, encontram-se entre os principais assuntos explorados por estudantes e pesquisadores da área (GOELDNER, RITCHIE e MCINTOSH, 2002).

Embora o turismo, como campo científico, ainda seja relativamente novo no Brasil, pois os primeiros cursos de graduação na área surgiram na década de setenta, conforme Panosso Netto (2005), a pesquisa nessa área vem crescendo nos últimos anos.

Enc. Bibli: R. Eletr. Bibliotecon. Ci. Inf., Florianópolis, n. esp., 2º sem. 2008 
Vários pesquisadores, como Barreto (1996), Rejowski (1993, 1998), Panosso Netto (2005) e Gomes e Rejowski (2005), têm-se preocupado em estudar a evolução da produção científica sobre turismo no país, principalmente em livros, teses e dissertações. Porém, não foram encontrados outros estudos sobre a evolução da produção científica relacionada a turismo, em anais de congressos e em artigos de periódicos acadêmicos específicos de turismo, nem de áreas afins que também estudam a atividade turística, além do artigo de Lopes e Alberton (2006), analisando a publicação das revistas Turismo e Análise e Turismo Visão e Ação.

Se bem que a publicação específica da área de turismo ainda seja limitada, o que pode ser explicado por ser um campo de estudo recente no país, se comparada a outras com maior tempo de desenvolvimento, existem publicações sobre o tema em diversas áreas, como a Geografia, Economia e Administração, por exemplo, que também estudam as atividades turísticas, e que precisam ser conhecidas a fim de que possam ser mais utilizadas pelos estudantes e pesquisadores dos cursos de turismo.

Em outros campos de estudo, como na economia (AZZONI, 1998, 2000) e na Administração (MACHADO-DA-SILVA, CUNHA e AMBONI, 1990; VERGARA, 1995; KEINERT, 2000; e LEAL, OLIVEIRA e SOLURI, 2003), à medida que a produção científica da área evolui, os próprios pesquisadores dedicam-se a analisar quantitativa e qualitativamente esta produção acadêmica, com a finalidade de descobrir quem, o que e onde se está pesquisando, e com qual relevância. Este tipo de análise, conhecida como estudo bibliométrico, é normal e freqüente em outros países, e busca-se através dele, uma avaliação aprofundada dessa produção, incluindo seu conteúdo, fontes citadas, trajeto de influência de autores, instituições de ensino superior (IES) que possuem grupos pesquisando o tema, e publicações que serviram de base à produção acadêmica em determinado período.

Ainda que o método bibliométrico não seja suficiente para avaliar a qualidade acadêmica dos trabalhos publicados, necessitando para isso de outros instrumentos de análise, a realização e a divulgação de estudos bibliométricos são importantes para que estudantes e pesquisadores saibam quais são os autores e periódicos mais citados, em que IES se concentram os estudos de determinado tema, e também servem para evidenciar limitações e potencialidades de melhoria da produção acadêmica da área, a serem debatidas em congressos e encontros científicos. Além disso, os estudos bibliométricos são muito utilizados para cálculo do fator de impacto da produção acadêmica de professores e alunos de programas de pós-graduação, indicador recentemente introduzido na avaliação de programas de pós-graduação do país, pela CAPES.

O fator de impacto é um indicador bibliométrico patenteado pelo Institute for Scientific Corporation - ISI, uma base de dados que coleta informações sobre publicações científicas há cerca de 40 anos. O fator de impacto de uma revista científica é calculado com base no número de vezes em que os artigos publicados nesse periódico, nos dois anos precedentes, foram citados como referências no ano considerado, dividido pelo número de artigos científicos publicados pela revista em questão nos dois anos anteriores (CAMPOS,2004).

Considerando a carência de estudos bibliométricos sobre turismo no Brasil, este trabalho teve como objetivo geral analisar a produção científica na área de turismo, publicada nos anais do ENANPAD - Encontro Anual da Associação Nacional de Pesquisa e Pós-Graduação em Administração, nos últimos dez anos. Especificamente, a pesquisa identificou o número de artigos publicados anualmente, os autores e as instituições de ensino às quais estão vinculados, bem como os temas e assuntos que estão sendo publicados por esses pesquisadores.

Além desta introdução, este trabalho encontra-se constituído de um referencial teórico, relacionado a estudos bibliométricos e turismo; na seqüência, descrevem-se a metodologia utilizada e os principais resultados da pesquisa; e conclui-se com algumas considerações a respeito do estudo realizado. 


\section{ESTUDOS BIBLIOMÉTRICOS E TURISMO}

A bibliometria é um conjunto de métodos de pesquisa desenvolvido pelas Ciências da Informação e Biblioteconomia, usado para mapear a estrutura do conhecimento de um campo científico e analisar o comportamento dos pesquisadores em suas decisões para construção desse conhecimento (VANTI, 2002). Utiliza análise quantitativa, estatística e de visualização de dados e técnicas como análises de citações, análise de co-citação, agrupamento bibliográfico, co-word analysis e Webometria.

O termo bibliometria (bibliometrics, em Inglês) foi introduzido por Allan Pritchard, em 1969, em seu artigo Statistical Bibliography or Bibliometrics, para designar a área de estudo que usa métodos matemáticos e estatísticos para investigar e quantificar os processos de comunicação escrita. Pritchard (1968) percebeu que a literatura é o ingrediente chave no processo do conhecimento e considera que bibliometria significa "todos os estudos que tentam quantificar os processos de comunicação escrita”. Publicações, autores, palavra-chave, usuários, citações e periódicos são alguns dos parâmetros observáveis em estudos bibliométricos da literatura.

Atualmente, os estudos bibliométricos são usados com maior freqüência em diversas áreas de conhecimento, inclusive na Administração, que conforme Rejowski (1998) constitui-se um dos campos de maior incidência de publicações sobre turismo. Essa incidência é compreensível, por duas razões. Em primeiro lugar, deve-se considerar que os estudos relacionados a temas como oferta e demanda turística, mercado turístico, planejamento, competitividade e qualidade de destinos turísticos, por exemplo, têm suas bases teóricas fortemente centradas na Economia e na Administração (Meira e Meira 2006).

Em segundo lugar, verifica-se que uma localidade só se transforma em um destino atrativo ao turista pela ação das organizações públicas e privadas nesse espaço geográfico. É o poder público, através de suas organizações, quem irá prover a região de condições mínimas de acesso e conforto ao turista, como estradas, aeroportos, redes de água, esgoto e energia elétrica. A iniciativa privada, por meio da oferta de hotéis, restaurantes, centros de compras e lazer é quem vai complementar a transformação dessa localidade em um destino turístico desejável. (GOELDNER, RITCHIE e MCINTOSH, 2002; COOPER et al., 2001).

Como o estudo das organizações (públicas, privadas e do terceiro setor) e suas relações com o mercado bem como o desenvolvimento e aplicação de tecnologias de gestão, nos diferentes setores econômicos, constitui-se a base dos estudos sistemáticos da Administração, é natural que os pesquisadores dessa área utilizem os fundamentos e os modelos teóricos já desenvolvidos na ciência administrativa para o estudo das organizações turísticas. Também é natural que os estudiosos da área de Turismo busquem na Administração (pública e privada) as bases teóricas para suas pesquisas tanto em destino quanto em organizações turísticas.

O crescimento quantitativo da produção acadêmica em administração no Brasil, nas últimas décadas, tem sido significativo. Com o aumento da exigência, pela Coordenação de Aperfeiçoamento de Pessoal de Nível Superior (CAPES), por produção docente e discente nos programas de pós-graduação, este crescimento acentuou-se na década de 1990, nos principais periódicos da área, conceituados na listagem QUALIS do referido órgão. Nesse período, o número de artigos aceitos no EnANPAD - Encontro da Associação Nacional de Pesquisa e Pós-Graduação em Administração cresceu em 144,3\% (TONELLI et al, 2003). Convém ressaltar que em 2007 este encontro apresentava-se em sua trigésima primeira versão e era classificado como um evento internacional "A", pela listagem Qualis da CAPES..

Este crescimento quantitativo provocou maior preocupação da comunidade acadêmica com a qualidade da produção científica, preocupação esta materializada em uma série de estudos bibliométricos, essencialmente críticos, iniciados pelo trabalho de Machado-da-Silva et al (1990), que avaliaram os artigos publicados em periódicos, na área de Organizações, no período de 1985 a 1989, concluindo pela fragilidade teórico-metodológica da área e pelo predomínio de uma orientação funcionalista.

Enc. Bibli: R. Eletr. Bibliotecon. Ci. Inf., Florianópolis, n. esp., $2^{\circ}$ sem. 2008 
A partir desse trabalho inicial, várias áreas temáticas da Administração passaram a fazer análises críticas de sua produção científica, como a área de Produção (Bignetti e Paiva, 1997), a de Administração da Informação (Hoppen et al, 1998), a de Marketing ( Perin et al, 2000; 2001; Froemming et al., 2000 e Vieira, 2003), a de Administração Pública (Keinert, 2000), a de Finanças (Leal, Oliveira e Soluri, 2003), e a de recursos Humanos (Tonelli,Caldas e Lacombe, 2003), com o objetivo de detectar problemas de qualidade a serem debatidos em eventos científicos. O Quadro 1 mostra o número de artigos sobre produção científica em Administração, já publicados no Brasil, por área, conforme estudo realizado por Graeml, Maciel e Macadar (2007), seguido dos respectivos debates que originaram.

\begin{tabular}{|l|l|}
\hline Áreas & $\begin{array}{l}\text { Número } \\
\text { de artigos }\end{array}$ \\
\hline Administração de Informação & 8 \\
\hline Recursos Humanos & 8 \\
\hline Marketing & 7 \\
Administração em geral & 6 \\
\hline Organizaçôes & 6 \\
\hline Produção & 4 \\
\hline Finanças & 3 \\
\hline Administração Pública & 2 \\
\hline Estratégia & 1 \\
\hline
\end{tabular}

Quadro 1 - Artigos sobre produção científica

Fonte: Adaptado de Graeml, Maciel e Macadar (2007)

Nesses estudos, foi utilizada a análise bibliométrica, com a finalidade de entender a influência de autores, instituições e países na produção acadêmica brasileira da área e, especificamente, examinar quais autores e instituições que mais estão produzindo; a integração de autores de diferentes IES; o nível de autocitação e citação de autores da própria instituição (endogenia); os padrões de referência dos principais autores; bem como os autores, veículos e IES mais citados.

A análise de citações, por exemplo, utilizada em diversos campos de conhecimento científico, serve para verificar se os autores estão lendo trabalhos de outros pesquisadores da própria área, se fogem do processo entrópico que a endogenia - provocada pela excessiva autocitação ou referência excessiva à produção do próprio programa - pode causar e, se estão evoluindo no processo de criação de redes interinstitucionais, evitando que a mesma pesquisa seja feita de forma isolada em universidades diferentes, conforme é recomendado nas diferentes áreas científicas.

A principal função das citações é fornecer ao leitor referências importantes sobre o campo de estudo em questão e mostrar a contribuição de autores predecessores para o trabalho atual (Caldas, Tino e Chui, 2003). Trata-se do reconhecimento formal do débito intelectual com os autores que trataram do tema anteriormente (Merton,1983).

No caso da área de turismo, os estudos bibliométricos sobre o que está sendo produzido a respeito do tema em diversas áreas também são necessários. O turismo é uma atividade complexa, por incluir diferentes grupos, como os próprios turistas, as empresas fornecedoras de bens e serviços, o governo e a comunidade anfitriã, que participam dessa atividade e que são por ela afetados. Segundo Goeldner, Ritchie e McIntoshi, (2002, p.23), o turismo é um conjunto de "atividades, serviços e setores que proporcionam uma experiência de viagem", e inclui os serviços de "transporte, hospedagem, alimentação, compras, entretenimento e outros serviços de hospitalidade disponíveis para indivíduos ou grupos" que estejam viajando para longe dos locais onde vivem. Em virtude dessa complexidade, a atividade turística é estudada sob o enfoque de várias ciências e essa diversidade de visões proporciona melhor

Enc. Bibli: R. Eletr. Bibliotecon. Ci. Inf., Florianópolis, n. esp., 2º sem. 2008 
compreensão do setor e das inter-relações entre seus componentes.

Como mencionado anteriormente, vários estudos sobre a produção científica em turismo já foram realizados por estudiosos da área. Barreto (1996), levantou os títulos específicos de turismo em bibliotecas de universidades e em editoras, constatando a escassez de livros na área, à época em que se realizou a pesquisa. Rejowski $(1993,1998)$ realizou um levantamento das teses em turismo, identificando, na ocasião, que estas se concentravam nas áreas de Geografia, Comunicação e Administração, porém, outras áreas como Sociologia e Antropologia começavam também a mostrar interesse em pesquisas sobre turismo.

Panosso Netto (2005) estudou as publicações sobre turismo, no Brasil, e constatou a existência de 17 editoras lançando livros sobre o tema e concluiu, que apesar de um crescente número de títulos na área, comercializados por estas editoras, ainda era baixo o número de publicações para atender às necessidades de estudos atualizados que a área apresenta. Gomes e Rejowski (2005) realizaram uma pesquisa em 336 teses sobre lazer no Brasil e identificaram que apenas 11 delas relacionavam-se a lazer turístico. As demais se referiam a lazer doméstico ou extradoméstico, sem nenhuma intersecção entre lazer e turismo.

A Associação Nacional de Pesquisa e Pós-Graduação em Turismo (ANPTUR) é recente e seu seminário anual encontra-se atualmente na quarta versão. A publicação de estudos bibliométricos quantitativos e qualitativos sobre turismo torna-se importante, a fim de que os pesquisadores da área se preocupem com os aspectos tratados pela bibliometria, os quais poderão dão suporte para reflexões e discussões sobre a qualidade da produção científica que está sendo apresentada.

É necessário, portanto, que estudantes e professores de programas de pós-graduação estejam cientes das atuais exigências por qualidade na produção acadêmica, pois, para que um trabalho seja aceito em um periódico indexado como de alto fator de impacto, o mesmo será avaliado com base nas características mencionadas. Isto se aplica particularmente ao turismo que, por ser uma área nova, ainda carece de estudos sobre a bibliografia científica, disponível na própria área e em áreas afins, que sirvam de suporte de argumentação para sua produção acadêmica.

\section{METODOLOGIA}

Para atingir os objetivos deste trabalho foi realizada uma pesquisa exploratório-descritiva, realizada por meio de dados secundários, no universo composto de todos os artigos apresentados nos encontros anuais do ENANPAD, nos últimos 10 anos, correspondente ao período compreendido entre 1997 e 2006, resultando em uma amostra composta de 67 artigos relacionados a turismo e hotelaria.

As variáveis de análise utilizadas foram o ano de publicação de artigo, a área temática, o nome do autor e respectiva IES, o título do trabalho, o objetivo, a metodologia, os principais resultados e conclusões. A análise de citações e de autores referenciados nos trabalhos, embora importantes nos estudos bibliométricos não serão aqui apresentados.

A operacionalização da pesquisa constou das seguintes etapas: a) inicialmente, foi realizada uma verificação preliminar, nos anais eletrônicos disponibilizados no site da ANPAD e $c d$ roms distribuídos nos seus congressos, no período mencionado; através do sistema de busca dos mesmos e utilizando as palavras-chave turismo, hospitalidade, hotelaria e hotel, foram identificados 67 artigos, seus códigos, áreas temáticas, resumos, e IES declaradas pelos autores, que foram inseridos em formulários próprios; b) a seguir, os 67 trabalhos foram analisados para identificar seus objetivos, tipo de pesquisa realizada, foco de análise , principais resultados e conclusões do trabalho, que também foram resumidos em formulários específicos; c) na seqüência, estes dados foram tabulados, agrupados e transformados em quadros, contendo a evolução do número de artigos, autores e instituições por ano de apresentação no citado encontro, bem como o número de artigos por área e ano de publicação.

Enc. Bibli: R. Eletr. Bibliotecon. Ci. Inf., Florianópolis, n. esp., 2º sem. 2008 


\section{RESULTADOS}

Os resultados da pesquisa encontram-se especificados a seguir, apresentando-se inicialmente a evolução do número de artigos, autores e IES ao longo dos 10 anos considerados, seguida da classificação dos mesmos por divisão acadêmica e áreas temáticas.

a) evolução da produção sobre turismo

Como se pode observar no Quadro 2, o número de trabalhos apresentados anualmente sobre turismo e temas relacionados sofreu um acréscimo de 500\% em 10 anos, passando de 3 em 1997 para 18 em 2006. O número de autores e respectivas IES que tiveram seus trabalhos selecionados e publicados nos Anais Eletrônicos (CD-ROM) do evento também cresceu de forma considerável. O número de autores por ano aumentou em quase $700 \%$ no período mencionado e o de IES representadas 300\%. Verifica-se ainda que este crescimento acentuouse a partir de 2004, nas três variáveis analisadas. Estes dados mostram o crescente interesse de pesquisadores de diversos cursos e IES sobre o tema.

\begin{tabular}{|ll|l|l|l|ll|l|l|l|l|}
\hline Ano & 1997 & 1998 & 1999 & 2000 & 2001 & 2002 & 2003 & 2004 & 2005 & 2006 \\
Artigos & 3 & 2 & 1 & 4 & 4 & 4 & 5 & 12 & 14 & 18 \\
\hline Autores & 5 & 4 & 1 & 9 & 10 & 7 & 11 & 21 & 33 & 39 \\
\hline IES & 4 & 3 & 1 & 5 & 7 & 4 & 7 & 18 & 14 & 16 \\
\hline
\end{tabular}

Quadro 2 - Evolução da produção sobre turismo no Enanpad

Um total de 114 diferentes autores publicou trabalhos sobre turismo no ENANPAD. Este número excede o de trabalhos, em virtude de vários artigos serem assinados por mais de um autor. Apenas 18 autores apresentaram mais de um artigo no período. Com três trabalhos por autor, aparecem Luiz Gustavo Medeiros Barbosa e Rivanda Meira Teixeira. Com dois artigos, cada, surgem Alketa Pecci, Benny Krama Costa, Carlos Alberto Freire Medeiros, Francisco Sávio de Oliveira Barros, Giovani Varzin, Glenda M Marques, Gustavo C de Souza, Jazan M Alves, João C da Cunha, Lindolfo G. Albuquerque, Manuela G Gueiros, Maria José Barbosa de Souza, Maria V C Moreira, Martinho I R Isnard, Rosana Mara Mazzaro e Siglind Kindl da Cunha. Os demais autores contribuíram com apenas um trabalho, cada um.

O número de autores por artigo encontra-se distribuído no quadro 3, mostrando a grande concentração de artigos assinados por dois autores.

\begin{tabular}{|l|l|l|}
\hline Autores por artigo & Número de artigos & Porcentagem \\
1 autor & 12 & 18,0 \\
\hline 2 autores & 40 & 59,7 \\
3 autores & 15 & 22,3 \\
\hline Total & 67 & 100,0 \\
\hline
\end{tabular}

Quadro 3 - Número de autores por artigo publicado

Verifica-se também, no referido quadro, um nimero reduzido da autoria individual como forma de comunicaçəo dos resultados das pesquisas sobre turismo no Enanpad. Isso pode significar maior concentraç^o em assuntos de interesse coletivo, que facilitam a produç^o conjunta, com maior troca de informaçes entre pesquisadores, que passam a discutir e divulgar os resultados de suas pesquisas em grupo. Pode também ser conseqüência da presşo pelo aumento da produçৎo cientsfica nas universidades brasileiras levando os pesquisadores a uma "troca de favores" ao convidarem outros colegas como co-autores, e vive-versa, conforme observam Graeml, Maciel e Macadar (2007) e Lunardi, Ramos e Maçada (2005). 
Segundo Graeml, Maciel e Macadar, (2007), o fato de um artigo passar pela andlise de diferentes autores, ainda que alguns deles atuem apenas como revisores, pode lhe trazer maior qualidade.

Com base nas informações declaradas pelos autores sobre as IES às quais estão vinculados, observou-se que as instituições que mais apresentaram trabalhos no evento, nos últimos dez anos, foram: a Universidade Federal do Rio Grande do Norte (UFRN) com 18 autores; seguida pela Fundação Getúlio Vargas (FGV) do Rio de Janeiro com 14; Universidade Federal de Pernambuco (UFPE) com 11; Universidade de São Paulo (USP) com 10; e Universidade do Vale do Itajaí (UNIVALI) com 9. Embora a maioria das universidades não possua programas específicos de pós-graduação em turismo, hospitalidade ou hotelaria, várias delas mantêm, em seus cursos de mestrado ou doutorado, linhas de pesquisa em turismo.

b) Distribuição dos artigos por divisões acadêmicas

No ano de 2006, o ENANPAD encontrava-se estruturado em 10 divisões acadêmicas, as quais se subdividiam em 30 áreas temáticas, conforme demonstrado no quadro 4. As divisões acadêmicas são de natureza mais permanente enquanto suas áreas temáticas possuem caráter mais temporário.

\begin{tabular}{|c|c|}
\hline Divisões Acadêmicas & Códigos e Áreas Temáticas \\
\hline Administração da Informação & $\begin{array}{l}\text { ADI-A - Administração de TI nas Empresas } \\
\text { ADI-B - Gestão de Ambientes virtuais } \\
\text { ADI-C - Impactos Socioculturais dos Sistemas de Informação }\end{array}$ \\
\hline $\begin{array}{l}\text { Administração Pública e Gestão } \\
\text { Social }\end{array}$ & $\begin{array}{l}\text { APS-A - Estado, Administração Pública e Sociedade Civil } \\
\text { APS-B - Gestão e Políticas Públicas } \\
\text { APS-C - Gestão Social e Ambiental }\end{array}$ \\
\hline Estratégia em Organizações & $\begin{array}{l}\text { ESO-A - Estratégia em Organizações } \\
\text { ESO-B - Gestão Internacional } \\
\text { ESO-C - Empreendedorismo e Comportamento Empreendedor }\end{array}$ \\
\hline Estudos Organizacionais & $\begin{array}{l}\text { EOR-A - Teoria das Organizações } \\
\text { EOR-B - Comportamento Organizacional } \\
\text { EOR-C - Gestão de Organizações e Desenvolvimento }\end{array}$ \\
\hline Finanças e Contabilidade & $\begin{array}{l}\text { FIC-A - Contabilidade para Usuários Externos } \\
\text { FIC-B - Contabilidade Gerencial e Controladoria } \\
\text { FIC-C - Mercados: Financeiro, Acionário e Risco } \\
\text { FIC-D - Finanças Corporativas }\end{array}$ \\
\hline $\begin{array}{l}\text { Gestão da Ciência, Tecnologia e } \\
\text { Inovação }\end{array}$ & $\begin{array}{l}\text { GCT-A - Administração de Ciência \& Tecnologia } \\
\text { GCT-B - Gestão de Tecnologia e Inovação } \\
\text { GCT-C - Empreendedorismo e Negócios Inovadores } \\
\text { GCT-D - Agregação de Valor e Agronegócios }\end{array}$ \\
\hline $\begin{array}{l}\text { Gestão de Pessoas e Relações de } \\
\text { Trabalho }\end{array}$ & $\begin{array}{l}\text { GPR-A - Gestão de Pessoas } \\
\text { GPR-B - Relações de Trabalho }\end{array}$ \\
\hline Gestão de Operações e Logística & $\begin{array}{l}\text { GOL-A - Operações Industriais e de Serviços } \\
\text { GOL-A - Gerenciamento da Cadeia de Suprimentos }\end{array}$ \\
\hline $\begin{array}{l}\text { Ensino e } \quad \text { Pesquisa em } \\
\text { Administração e Contabilidade }\end{array}$ & $\begin{array}{l}\text { MKT-A - Teorias, Modelos e Metodologias de Marketing } \\
\text { MKT-B - Comportamento, Dimensionamento e Previsão } \\
\quad \text { de Mercado } \\
\text { MKT-C - Atividades, Aplicações e Técnicas de Marketing } \\
\text { EPQ-A - Ensino e Pesquisa em Administração } \\
\text { EPQ-B - Ensino e Pesquisa em Contabilidade }\end{array}$ \\
\hline
\end{tabular}

Quadro 4 - Divisões acadêmicas e áreas temáticas do EnANPAD.

Enc. Bibli: R. Eletr. Bibliotecon. Ci. Inf., Florianópolis, n. esp., 2º sem. 2008 
O conhecimento das divisões acadêmicas e respectivas áreas temáticas do EnANPAD poderá ser útil a professores e alunos dos programas de pós-graduação em turismo, interessados em submeter seus trabalhos de pesquisa ao referido congresso e discuti-los com a comunidade acadêmica.

O quadro 5 mostra a distribuição dos artigos sobre turismo por divisão acadêmica, apresentados no ENANPAD, indicando que o maior número de trabalhos publicados no período versavam sobre Administração Pública e Gestão Social (num total de 19), Marketing (14), Estratégia em Organizações (11), Estudos Organizacionais (8) e Gestão de Pessoas e Relações do Trabalho (6). As demais divisões apresentaram 3 artigos ou menos, cada uma. Observa-se que as três primeiras divisões juntas responderam por mais de $65 \%$ dos artigos sobre turismo apresentados no referido congresso.

\begin{tabular}{|c|c|c|}
\hline Divisão Acadêmica & \begin{tabular}{|l}
$\begin{array}{l}\text { Número de } \\
\text { artigos }\end{array}$ \\
\end{tabular} & Porcentagem \\
\hline $\begin{array}{l}\text { Administração Pública e Gestão Social } \\
\text { Marketing }\end{array}$ & $\begin{array}{l}19 \\
14\end{array}$ & $\begin{array}{l}28,35 \\
20,89\end{array}$ \\
\hline Estratégia em Organizações & 11 & 16,41 \\
\hline Estudos Organizacionais & 8 & 11,94 \\
\hline Gestão de Pessoas e Relações de Trabalho & 6 & 8,95 \\
\hline Finanças e Contabilidade $(*)-$ & 3 & 4,47 \\
\hline Administração da Informação & 2 & 2,98 \\
\hline Gestão da Ciência, tecnologia e Inovação & 2 & 2,98 \\
\hline Gestão de Operações e Logística & 2 & 2,98 \\
\hline Total & 67 & 100,00 \\
\hline
\end{tabular}

Quadro 5 - Distribuição dos artigos sobre turismo por divisão acadêmica do EnANPAD.

Os trabalhos publicados em anais de anos anteriores, cujas áreas possuíam nomenclaturas diferentes, mas tratavam do mesmo tema, foram agrupados na área atual correspondente. No ano de 2006 o evento recebeu 3214 submissões de trabalhos de 15 países, por se tratar de em encontro internacional, dos quais foram selecionados apenas 848 , correspondendo a $26,38 \%$ do total.

c) Temas e objetivos dos artigos analisados

A seguir serão comentados os assuntos que foram objeto de interesse dos pesquisadores nas áreas que publicaram um maior número de trabalhos no evento. Em geral, o foco de análise desses artigos foi principalmente o turista e seu comportamento, as organizações hoteleiras, bem como o planejamento e a gestão dos destinos.

Os trabalhos apresentados na divisão de Políticas públicas e Gestão Social tratavam de turismo e desenvolvimento sustentável; práticas de responsabilidade social nas organizações turísticas; gestão ambiental; impactos econômicos do turismo no desenvolvimento local; percepção da população receptora sobre impactos negativos do turismo na localidade; modelos de competitividade turística e sustentabilidade; mudanças nas estratégias brasileiras de desenvolvimento; governança em clusters turísticos; políticas públicas em turismo e capital social em aglomerados produtivos turísticos.

Em Marketing, os trabalhos versavam sobre a imagem do Brasil como destino turístico; avaliação de programas de marketing de destinos; avaliação do mercado brasileiro para turismo de negócios; cenários de serviços e gerenciamento de impressões em serviços turísticos; turista da terceira idade; percepção do turista a respeito da segurança na escolha de destinos turísticos; estímulos sensoriais e experiências de consumo nos portais da WEB e Internet; risco percebido na compra on line; distribuição eletrônica de serviços de hotelaria; e satisfação e fidelidade dos turistas. 
Na divisão de Estratégia em Organizações os artigos referiam-se a planejamento estratégico de turismo municipal; modelos de avaliação de impactos do turismo e desenvolvimento local; utilização de recursos da WEB para vantagem competitiva; comportamento empreendedor de micros e pequenas empresas turísticas; fatores de atratividade de locais turísticos; valores institucionais e estratégias de órgãos oficiais de turismo; e avaliação da oferta para análise estratégica de empresas hoteleiras.

Os trabalhos submetidos à divisão de Estudos Organizacionais tratavam de empreendedorismo em turismo; auto-organização; comprometimento em organizações hoteleiras; ambiente organizacional; bem como das relações e desempenho dos agentes organizacionais em agroturismo.

Os artigos da divisão de Gestão de Pessoas e Relações do Trabalho abordavam qualidade de vida no trabalho; políticas e práticas de Recursos Humanos; treinamento e padronização de serviços em hotéis; satisfação dos funcionários; planejamento de mão-de-obra para o setor hoteleiro; cliente interno; função gerencial em hotéis; e comprometimento organizacional e desempenho.

No Quadro 6 pode-se visualizar o código e o nome das respectivas áreas temáticas do ENANPAD nas quais foram publicados trabalhos, ao longo dos 10 anos pesquisados. Destaca-se que a partir de 2005 as áreas incorporaram outros temas, o que provavelmente deve ter ocasionado o maior número de submissões e aprovações de artigos sobre turismo. Este quadro poderá ser utilizado por pesquisadores interessados em localizar trabalhos sobre turismo nos anais eletrônicos do ENANPAD.

\begin{tabular}{|l|l|l|}
\hline \multirow{2}{*}{ Ano } & Código e Área Temática & $\mathbf{N}^{\mathbf{0}}$ de Artigos \\
\hline 1997 & AR - Administração Rural e Agroindustrial & 1 \\
& EST - Organizações e Estratégia & 1 \\
& MKT- Marketing & 1 \\
\hline 1998 & MKT - Marketing & 1 \\
& OLS - Operações, Logística e Serviços & 1 \\
\hline 1999 & MKT- Marketing & 1 \\
\hline 2000 & ADE - Administração Estratégica & 1 \\
& ADI - Administração da Informação & 1 \\
& MKT- Marketing & 1 \\
& OLS - Operações, Logística e Serviços & 1 \\
\hline 2001 & ESO- Estratégia em Organizações & 2 \\
& CCG - Contabilidade e Controle Organizacional & 1 \\
& TEO- Teoria das Organizações & 1 \\
\hline 2002 & TEO - Teoria das Organizações & 1 \\
& ADI - Administração da Informação & 1 \\
& GRT - Gestão de Pessoas e Relações do Trabalho & 2 \\
\hline 2003 & POP- Políticas Públicas & 2 \\
& GSA - Gestão Social e Ambiental & 2 \\
& MKT Marketing & 1 \\
\hline 2004 & COR Organizações/Comportamento Organizacional & 1 \\
& ESO Estratégia em Organizações & 2 \\
& GRT Gestão de Pessoas e Relações do Trabalho & 3 \\
& MKT - Marketing & 5 \\
& POP - Políticas Públicas & 1 \\
\hline 2005 & APS-A Estado, Administração Pública e Sociedade & 2 \\
& APS-B Gestão e Políticas Públicas & 1 \\
& APS-C Gestão Social e Ambiental & 4 \\
& ESO-A Estratégia em Organizações & 4 \\
\hline & ESO-C Empreendedorismo e Comportamento Empreendedor & 1 \\
\hline
\end{tabular}

Enc. Bibli: R. Eletr. Bibliotecon. Ci. Inf., Florianópolis, n. esp., 2º sem. 2008 


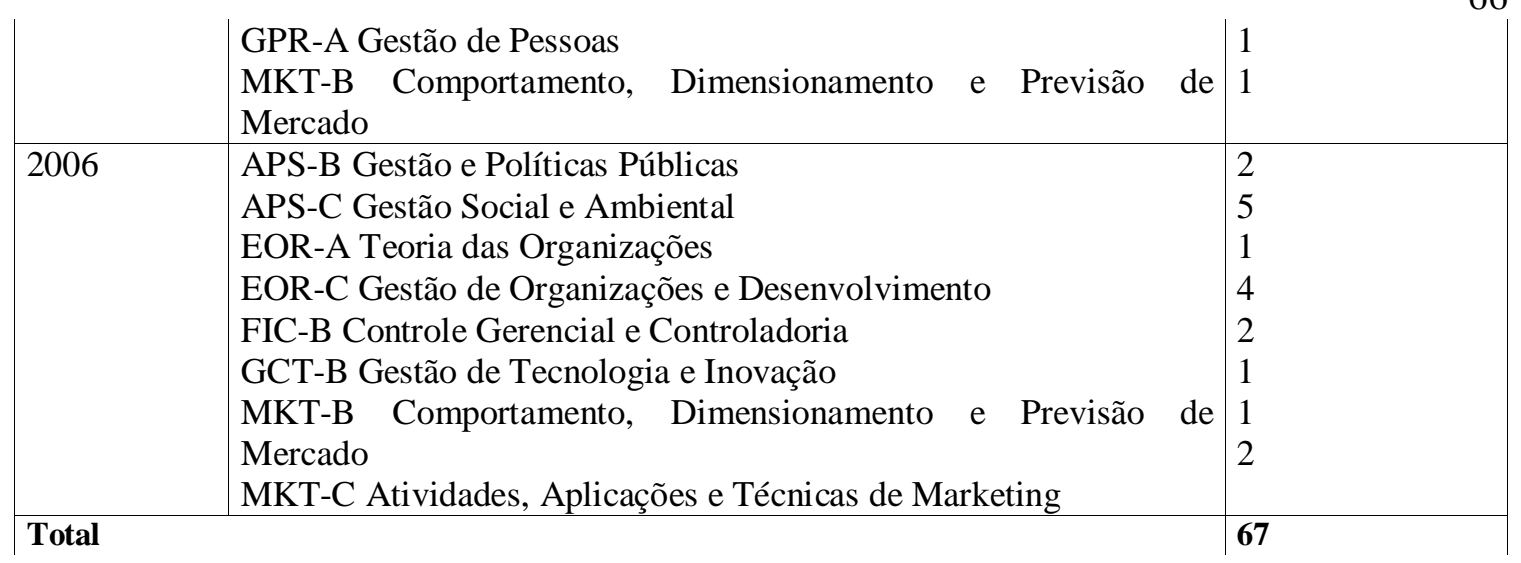

Quadro 6 - Códigos dos trabalhos e áreas de submissão distribuídos por ano

A seguir, será apresentado um resumo dos objetivos que os estudos se propunham a atingir, nas três divisões que apresentaram maior número de trabalhos sobre turismo.Essa descrição pode ser útil aos pesquisadores que estão desenvolvendo trabalhos semelhantes ou pretendem realizar estudos comparativos sobre esses assuntos.

Os artigos submetidos às diversas áreas temáticas da divisão de Administração Pública e Gestão Social apresentavam os seguintes objetivos: identificar os fatores relacionados com o grau de aderência das práticas ambientais na gestão hoteleira; descrever os elementos da oferta turística que influenciam o turista a manifestar a intenção de voltar à cidade; identificar as dificuldades e mudanças que ocorreram em um destino turístico que se refletem no comportamento da população, na preservação das culturas locais e em novas formas de inserção social; desenvolver metodologia para elaboração de roteiros turísticos; propor um modelo de governança em um cluster turístico; analisar a organização dos atores (econômicos, políticos e sociais) em um arranjo produtivo turístico; analisar a contribuição das políticas públicas para o desenvolvimento sustentável do turismo; apresentar um modelo de análise dos impactos econômicos do turismo; analisar a qualidade dos serviços turísticos em um destino; identificar os impactos do turismo na percepção dos atores sociais; analisar modelos de competitividade para destinos turísticos; e discutir as estratégias públicas do turismo em uma localidade.

Os estudos relativos às áreas da divisão de Marketing se propunham a: detectar os fatores que, na percepção dos hoteleiros, contribuem para o desenvolvimento de sua atividade; discutir a satisfação do consumidor da terceira idade em serviços de hotelaria; analisar o posicionamento das cadeias multinacionais de hotéis na avaliação da atratividade do mercado hoteleiro brasileiro para negócios; analisar os aspectos do comportamento do turista estrangeiro e sua percepção sobre segurança; estudar como os internautas percebem os estímulos de experiências virtuais em portais turísticos; descrever os procedimentos adotados e os resultados obtidos no desenvolvimento da escalas para mensurar o risco percebido em por consumidores em compras on-line de serviços hoteleiros; analisar o papel dos cenários de serviços no gerenciamento de impressões em serviços de hospitalidade; estudar os fatores que influenciam a satisfação e a lealdade do turista; verificar como a indústria hoteleira responde a solicitações de informações via correio eletrônico; analisar a imagem do Brasil como destinação turística, na percepção do viajante britânico; estudar o bem-estar espiritual do turista peregrino; avaliar a adequação das metodologias utilizadas e os programas de marketing de uma destinação turística analisar as características desejáveis de sistemas de distribuição eletrônica de hotéis.

Os trabalhos publicados nas áreas que compunham a divisão de Estratégias em Organizações tinham como objetivos: analisar a oferta turística de um destino do ponto de vista dos 
empresários que atuam no setor; apresentar um modelo de análise estratégica em empresas hoteleiras; avaliar a possibilidade de crescimento e desenvolvimento do turismo de negócios em um destino, utilizando o modelo g diamante $\square$ h de Porter; diagnosticar o potencial do turismo na cidade de Lavras; analisar a influência dos valores institucionalizados no contexto ambiental e dos valores compartilhados pelos dirigentes sobre as estratégias de ação desenvolvidas pelos órgãos oficiais de turismo; analisar a concorrência hoteleira na praia de Muro Alto; avaliar o grau de interação, competitividade e sustentabilidade de um cluster turístico; analisar como os hotéis estão utilizando os recursos da world wide para obtenção de vantagem competitiva; analisar as formas de utilização da Internet pelos hotéis em seu relacionamento com os clientes; e analisar a organização produtiva de PMEs atuantes nos segmento turístico da região de Canoa Quebrada(CE), sob a ótica do comportamento empreendedor.

\section{CONSIDERAÇÕES FINAIS}

A pesquisa realizada com os artigos publicados nos Anais dos ENANPAD, no período compreendido entre 1997 e 2006, revelou a existência de 67 artigos publicados por pesquisadores da área de Administração, em diversas áreas temáticas, relacionados principalmente à gestão pública e social no setor turístico, marketing de empresas e destinações, e estratégia empresarial e setorial, entre outras também importantes.

Estes trabalhos fornecem uma visão do turismo sob o enfoque da necessidade de adaptação das organizações públicas e privadas que fazem parte do setor às variáveis econômicas, sócioculturais, ambientais, tecnológicas e demográficas, que compõem o ambiente externo no qual as organizações de qualquer setor econômico precisam operar. Alguns deles, apresentam e discutem resultados de pesquisas utilizando modelos de diagnósticos, planejamento, gestão e avaliação de resultados, usados com freqüência em setores tradicionais, porém aplicados ao turismo.

Embora estes trabalhos não sejam a única forma de se estudar o turismo, o conhecimento dos mesmos por pesquisadores da área pode auxiliar a compreensão de uma atividade tão complexa. Além disso, servem também para saber em quais IES se encontram os núcleos de pesquisa em turismo a fim de estabelecer redes de contatos para troca de informações e realização de trabalhos conjuntos, multidisciplinares e interinstitucionais.

No decorrer do trabalho, foi possível verificar a utilidade dos sistemas informatizados de busca, em pesquisa acadêmica, como o programa iANPAD, para que alunos, pesquisadores e professores se informem a respeito da evolução dos temas que estão sendo alvo de interesse da comunidade científica, na área de Administração.

Os resultados desta pesquisa são relevantes para a construção do conhecimento científico sobre turismo, mas, deve-se considerar como limitação do estudo o fato de haver sido realizado utilizando-se apenas uma única fonte de informação que foram os Anais Eletrônicos do congresso EnANPAD. Por esta razão, sugere-se que outros estudos sobre turismo sejam feitos nas demais publicações científicas da área da Administração bem como em outros campos científicos que estudam o turismo, principalmente naqueles periódicos que possuam os mais altos conceitos na listagem Qualis da Coordenação de Pós-graduação do Ensino Superior (CAPES).

\section{REFERÊNCIAS}

AZZONI, C. R. "Clássicos" da literatura econômica brasileira: trabalhos e autores mais citados nas nossas revistas acadêmicas. Economia Aplicada, v.2, n.4, p.771-780. 1998.

AZZONI, C. R. Desempenho das revistas e dos departamentos de economia brasileiros segundo publicações e citações recebidas no Brasil. Economia Aplicada, v.4, n.4., 2000.

Enc. Bibli: R. Eletr. Bibliotecon. Ci. Inf., Florianópolis, n. esp., $2^{\circ}$ sem. 2008 
BARRETO, M. Produção bibliográfica em turismo no Brasil. Revista Turismo em Análise. São Paulo: v.7. n.2., p.97-102, Nov. 1996.

BIGNETTI, L. P.; PAIVA, E. L. Estudo das citações de autores de estratégia na produção acadêmica brasileira. In: Encontro Anual da Associação Nacional de Pesquisa e PósGraduação em Administração - ENANPAD, 21, 1997.. Anais... : ANPAD, 1997.

BOTELHO, D.; MACERA, A. Análise metateórica de teses e dissertações da área de marketing apresentadas na FGV-EAESP (1974-1999). In: Encontro Anual da Associação Nacional de Pesquisa e Pós-Graduação em Administração - ENANPAD, 25, 2001, Campinas.

Anais... Campinas: ANPAD, 2001. 1 CD-ROM.

CALDAS, M. P.; TINOCO, T; CHU, R. A. Análise bibliométrica dos artigos de RH publicados no ENANPAD na década de 1990: um mapeamento a partir das citações dos heróis, endogenias e jactâncias que fizeram a história recente da produção científica da área. In: Encontro Anual da Associação Nacional de Pesquisa e Pós-Graduação em Administração - ENANPAD, 27º, 2003, Atibaia. Anais... Atibaia: ANPAD, 2003, 1 CD-ROM.

CAMPOS, M. Conceitos Atuais em Bibliometria. Arquivos Brasileiros de Oftalmologia, v.66, n.1., p.18-22. Encarte p.65. Disponível em: http://.abonet.com.br/abo/666s/edit07.pdf Acesso em 29/5//07.

COOPER, C.; FLETCHER, J.; WANHILL, S.; GILBERT, D.; SHEPHERD, R. Turismo: princípios e práticas. 2. ed. Porto Alegre: Bookman, 2001.

FROEMMING, L. M. S.; LUCE, F. B.; PERIN, M. G.; SAMPAIO, C. H.; BEBER, S. J. N.; TREZ, G. Inventário de artigos científicos na área de marketing no Brasil. Revista de Administração Contemporânea, v.4., n.2., p. 159-173, 2000.

GOLDNER, C. R.; RITCHIE, J. R. B.; MCINTOSH, R. R. Turismo: princípios, práticas e filosofias. $8^{\mathrm{a}}$ edição, Porto Alegre: Bookman, 2002.

GOMES, C. R.; REJOWSKI, M. Bases documentais e teóricas do lazer turístico no Brasil: In; Seminário da ANPTUR, 2, 2005. Balneário Camboriú. Anais... Balneário Camboriú: ANPTUR, 2005, 1 CD-ROM.

GRAEML, A. R.; MACIEL, H. F. MACADAR, M. A. Análise das citações utilizadas em ADI: 10 Anos de amais digitais do ENANPAD (1997-2006). In: Encontro Anual da Associação Nacional de Pesquisa e Pós-Graduação em Administração - ENANPAD, 31. Anais... Rio de Janeiro: ANPAD, 2007.

HOPPEN, N.; AUDY, J. L. N.; ZANELA, A. I. C; CANDOTTI, C. T.; SANTOS, A. M.; SCHEID, R; PERIN, M. G.; MECCA, M. S.; PETRINI, M. Sistemas de Informação no Brasil: uma análise dos artigos científicos dos anos 90. In: Encontro Anual da Associação Nacional de Pesquisa e Pós-Graduação em Administração - ENANPAD, 22, 1998, Foz de Iguaçu. Anais... Foz de Iguaçu: ANPAD, 1998.

KEINERT, T.M.; O que é administração pública no Brasil? In: Encontro Anual da Associação Nacional de Pesquisa e Pós-Graduação em Administração - ENANPAD, 24, 2000, Florianópolis. Anais... Florianópolis: ANPAD, 2000, 1 CD-ROM.

LEAL, R.; OLIVEIRA, J. SOLURI, A. Perfil da pesquisa em Finanças no Brasil: Revista de Administração de Empresas, v.43, n.1., p.91-104, 2003.

LOPES, V. J.; ALBERTON, A. Publicações científicas em Turismo: uma análise dos artigos publicados nas revistas Turismo em Análise e Turismo, Visão e Ação. In: Seminário de Iniciação Científica da Universidade do Vale do Itajaí, 5², 2006, São José (SC). Anais... São José: UNIVALI, 2006.

LUNARDI, G.L.; RAMOS, R. L.; MAÇADA, A. C. F. Pesquisa em Sistemas de informação: uma análise a partir dos artigos publicados no ENANPAD e nas principais revistas nacionais de administração. In: Encontro da Associação Nacional de Pesquisa e Pós-Graduação da ANPAD, ENANPAD, 29, 2005, Brasília. Anais... Brasília: ANPAD, 2005.

MACHADO-DA-SILVA, C. L.; CUNHA, V. C.; ANBONI, N. Organizações: o estado da arte da produção acadêmica no Brasil: In: ENANPAD - Encontro da Associação Nacional de 
Pesquisa e Pós-Graduação da ANPAD, 14, 1990, Florianópolis. Anais... Florianópolis: ANPAD, 1990.

MEIRA, F. B.; MEIRA, M. B. V. Considerações sobre um campo científico em formação: Bourdieu e a $\square$ gnova ciência $\square$ h do turismo. In: Encontro da Associação Nacional de Pesquisa e Pós-Graduação da ANPAD - ENANPAD, 14, 2006, Salvador. Anais... Salvador: ANPAD, 1990.

MERTON, R. K. Foreword. (Garfield. E.). Citation indexing - its theory and application in science, technology, and the humanities. Philadelphia: ISI Press, p.vi, 1983.

PANOSSO NETO, A. Publicações em turismo no Brasil: In: Seminário da ANPTUR, 2, 2005, Balneário Camboriú. Anais... Balneário Camboriú: ANPTUR, 2005. 1 CD-ROM.

PERIN, M. G.; SAMPAIO, C. H. FROEMMING. L. M. S.; LUCE, F. B. A pesquisa survey em artigos de marketing nos ENANPADs da década de 90. In: Encontro Anual da Associação Nacional de Pesquisa e Pós-Graduação em Administração - ENANPAD, 24, 2000, Florianópolis. Anais... Florianópolis: ANPAD, 2000, 1 CD-ROM

PRITCHARD, A. Statistical bibliography or bibliometrics? Journal of Documentation, [s.1.], v.25, n.4., p. 348-349, Dec. 1969.

REJOWSKI, M. Realidade versus necessidades da pesquisa turística no Brasil. Revista Turismo em Análise. São Paulo: v.9, n.1., p.82-91., maio 1998.

REJOWSKI, M. Pesquisa acadêmica em turismo no Brasil (1975 a 1992): Configuração e sistematização documental. São Paulo: Escola de Comunicação e Artes. Universidade de São Paulo (Tese de Doutorado), 1993.

TONELLI, M. J.; CALDAS, M. P.; LACOMBE, B. M. B. Produção acadêmica em Recursos Humanos no Brasil: 1991-2000. São Paulo: Revista de Administração de Empresas. São Paulo: jan/fev/mar, 2003, p.105-122.

VANTI, N. Da bibliometria à webometria: uma exploração conceitual dos mecanismos utilizados pra medir o registro da informação e a difusão do conhecimento. Ciência da Informação. Brasília: v.31, n.2., p. 152-162, maio/ago. 2002

VERGARA, S. C. CARVALHO JR., D. de S. Nacionalidade dos autores referenciados na literatura brasileira sobre organizações: In: Encontro Anual da Associação Nacional de Pesquisa e Pós-Graduação em Administração - ENANPAD, 19, 1995, João Pessoa. Anais... João Pessoa: ANPAD, 1995, Vol.6., p.169-188.

VIEIRA, F. G. Narciso sem espelho: a publicação brasileira de marketing. Revista de Administração de Empresas, v.43, n.1., p. 81-90, 2003.

\section{ABSTRACT}

Academic production presented in scientific events represents important database for studying, and information technology using bibliometrics contributes to research about the evolution of these production, so bibliometric studies are useful tools for the assessment of production of a group of researchers about a specific topic in any given period of time. With the aim of analyzing scientific production in tourism area, published by the annals of EnANPAD - Encontro da Associação Nacional de Pesquisa e Pós-Graduação em Administração (Meeting of the National Association of Research and Post Graduates in Administration), between 1997 through to 2006, a bibliometric study was carried out, in a descriptive-exploratory manner, identifying 67 articles about tourism and hospitality presented in the event, on that period, and expressive evolution was verified in quantity of works presented annually, growing from 3 articles in 1997 to a number of 18 in 2006. Research shown also that authors that were publishing on the said event, and the institutions to which they belong and topics related to tourism that are raising the interest of academic community. 
Key words: Tourism; Tourism research; Bibliometric studies

Originais recebidos em: 30/09/2008

Texto aprovado em: 06/11/2008

Enc. Bibli: R. Eletr. Bibliotecon. Ci. Inf., Florianópolis, n. esp., 2º sem. 2008 